Check for updates

Cite this: RSC Adv., 2018, 8, 25201

Received 27th February 2018

Accepted 2nd July 2018

DOI: $10.1039 / c 8 r a 01745 j$

rsc.li/rsc-advances

\section{Extraction in cholinium-based magnetic ionic liquid aqueous two-phase system for the determination of berberine hydrochloride in Rhizoma coptidis $\uparrow$}

\begin{abstract}
Li-rong Nie, ${ }^{\text {ab }}$ Hang Song, ${ }^{a}$ Alula Yohannes, ${ }^{a}$ Siwei Liang ${ }^{a}$ and Shun Yao (DD *a
A magnetic ionic liquids (MILs)-based aqueous two-phase system (MIL-ATPs) obtained by mixing with a series of inorganic salts, which involves five cholinium MILs with the piperidinyloxy radical anion is reported for the first time. Phase diagrams for the new ATPs were experimentally determined at different temperatures (298.15-318.15 K) and the liquid-liquid equilibrium data for two-phase systems were correlated according to the empirical nonlinear expression. The effects of the types of MILs, temperature and inorganic salts on the binodal curve are discussed in detail. The MIL-ATPs coupled with HPLC-UV analysis was developed in the quantitation of berberine hydrochloride in Rhizoma coptidis. Under optimal conditions, the partition coefficient of berberine hydrochloride was 127.68 with the precision values (RSD\%) of $1.40 \%$ and $2.83 \%$ for intra-day $(n=6)$ and inter-day $(n=3)$, respectively. The limit of detection (LOD) and limit of quantification (LOQ) for berberine hydrochloride were $0.023 \mathrm{mg} \mathrm{L}^{-1}$ and $0.077 \mathrm{mg} \mathrm{L}^{-1}$, respectively. The recoveries were obtained in the acceptable range of $97.4-101.2 \%$. Moreover, the content of berberine hydrochloride in the raw material of Rhizoma coptidis was measured as $123.95 \mathrm{mg} \mathrm{g}^{-1}$ with this method. Finally, 99.8\% MIL was recovered for cycle application after the removal of berberine hydrochloride by using D101 resin. This study provides a meaningful reference for the application of MIL-ATPs with great prospects.
\end{abstract}

\section{Introduction}

Rhizoma coptidis is a kind of medicinal plant that grows widely in China. Its main active ingredient is berberine, which is usually applied in clinic preparations as an antidiarrheal, antiinflammatory and antimicrobial constituent., ${ }^{\mathbf{1 , 2}}$ More importantly, it has been found that berberine can induce apoptosis and inhibit human neuroblastoma cell growth. ${ }^{3-6}$ In the last few decades, the conventional extraction and separation methods for berberine have primarily been performed by using organic solvent extraction, ultrasound-assisted extraction and supercritical fluid extraction. ${ }^{7,8}$ Moreover, some functional nanoparticles have been used for the selective extraction of berberine in recent years. ${ }^{\mathbf{9 1 0}}$ However, these extraction techniques have some limitations and disadvantages such as high cost/ consumption, low extraction efficiency, or long extraction time. Therefore, more and more researchers are focusing on improving and optimizing the extraction and separation techniques for the extraction of active components from natural

${ }^{a}$ School of Chemical Engineering, Sichuan University, Chengdu 610065, P. R. China. E-mail: Cusack@scu.edu.cn

${ }^{b}$ School of Medical Instrument and Food Engineering, University of Shanghai for Science and Technology, Shanghai 200093, China

$\dagger$ Electronic supplementary information (ESI) available. See DOI: 10.1039/c8ra01745j products. Among them, the aqueous two-phase system (ATPs) is known as an economical and efficient extraction/(re) concentration/purification technique, which has been popularly applied in the study of various bioactive compounds, such as proteins, ${ }^{11}$ metal ions, ${ }^{12}$ antibiotics, ${ }^{13}$ dyes ${ }^{14}$ and so on. In fact, it is a liquid-liquid process capable of separating these target compounds. Compared with conventional extraction methods, ATPs is more environmentally benign and does not use any harmful volatile organic solvents in the entire process. In 2003, Rogers and co-workers found that ionic liquids (ILs) could be used to form ATPs by mixing with inorganic salts, and the ILs-based ATPs have many advantages such as short phaseformed time, low viscosity, little emulsion, good recyclability and environmental friendliness. ${ }^{15}$

In the past few years, ILs-ATPs have attracted the attention of more and more researchers. Among them, the imidazoliumbased ILs-ATPs have been the most reported by many research groups. By virtue of the above advantages, they have been successfully applied to the extraction of many bioactive molecules and drugs, ${ }^{15-21}$ and can pull target constituents into the top or bottom phase and avoid the interference of impurities in the determination of target compounds. Innovation in this field mainly originates from two aspects, namely, the new extraction mode, or new ILs with special structures and properties. The former is like the research of Zhang and co-workers, ${ }^{22}$ and the alkaloids from Sophora flavescens were extracted and purified 
based on the microwave-assisted aqueous two-phase extraction. As for the latter, our group has recently found that tropiniumbased and quinolinium-based ILs can form ATPs when mixed with salts, and they were employed in the extraction of bioactive ginseng saponins and $99.5 \%$ extraction efficiency was obtained. $^{23}$ Cholinium-based ILs are environmentally friendly phase-forming candidates. ${ }^{24-26}$ More importantly, a previous study also indicated that this kind of ILs possesses remarkable biodegradability as well as lower toxicity. ${ }^{27}$ As a successful example, the ATPs composed of polyethylene glycol (PEG) and cholinium-based salts have also been successfully applied in the extraction of tetracycline from fermentation broth with extraction efficiency $>80 \%{ }^{28}$ Furthermore, more and more liquid-liquid equilibrium data from ionic liquids/water aqueous two-phase systems are being measured and correlated with empirical equations, which lays the solid foundation for their broader application in separation science.

Remarkable progress has been made in the field of magnetic ILs (MILs), ${ }^{29}$ and the related aqueous two-phase systems (MILATPs) are stimulating interest. ${ }^{30}$ Under the effect of an external magnetic field, the phase assembly and separation become more time-saving and easier, which make these systems superior to the common IL-ATPs. However, new MILATPs with various phase behaviours have scarcely been reported so far and their application for more bioactive natural products in herbal samples is expected. In order to realize the efficient extraction of berberine hydrochloride in Rhizoma coptidis, the structure and properties of MIL are very crucial. In our preliminary screening, it was found that the MILs containing the popular imidazole cation or the Fe(III) anion cannot form ideal ATPs. According to our recent investigation on the related properties and solubility behaviour of cholinium-based MIL, ${ }^{31}$ the combination of this kind of MIL and ATPs was finally selected to achieve satisfactory performance for target analytes. ATPs formed by this kind of MILs can achieve ideal phase assembly and separation, while the cation with small volume can result in stronger magnetism. Based on the above research background, five cholinium-based organic magnetic ionic liquids have been prepared to develop the MIL-ATPs coupled with HPLC-UV in the application of herbal analysis. The ATPs were explored by mixing with inorganic salts, including $\mathrm{K}_{3} \mathrm{PO}_{4}$, $\mathrm{K}_{2} \mathrm{HPO}_{4}, \quad \mathrm{~K}_{2} \mathrm{CO}_{3}, \quad \mathrm{~K}_{3} \mathrm{C}_{6} \mathrm{H}_{5} \mathrm{O}_{7}$ and $\mathrm{Na}_{3} \mathrm{C}_{6} \mathrm{H}_{5} \mathrm{O}_{7}$. Furthermore, related binodal curves were correlated according to the empirical nonlinear expression. The effects of the types of MILs, inorganic salts and temperature on the phase diagram and tielines are discussed, and the above MIL-ATPs coupled with highperformance liquid chromatography (HPLC) have been successfully applied to the extraction and quantitation of berberine hydrochloride in Rhizoma coptidis. The extraction process was optimized using the single factor experiment, and the adsorption of MIL on resin for its reuse was also studied.

\section{Experimental section}

\subsection{Material and reagents}

All reagents and solvents were of analytical grade or higher. Ethanol, acetone, dichloromethane, silver nitrate, hydrochloric acid, phosphoric acid, $\mathrm{K}_{3} \mathrm{PO}_{4}, \mathrm{~K}_{2} \mathrm{HPO}_{4}, \mathrm{~K}_{2} \mathrm{CO}_{3}, \mathrm{Na}_{3} \mathrm{C}_{6} \mathrm{H}_{5} \mathrm{O}_{7}$ and $\mathrm{K}_{3} \mathrm{C}_{6} \mathrm{H}_{5} \mathrm{O}_{7}$ were purchased from Kelong Chemical reagents factory (Chengdu, China). 4-Hydroxy-2,2,6,6-tetramethyl piperidine 1-oxyl free radical (piperidinyloxy radical, 4-OH-TEMPO), chlorosulfonic acid, bromoethane, bromopropane, bromobutane and bromopentane was purchased from Aladdin Chemical reagent Co. Ltd. (Shanghai, China). The standard compound berberine hydrochloride (purity $\geq 99 \%$ ) was purchased from Mansite Bio-Technology Co. Ltd. (Chengdu, China).

\subsection{Apparatus}

All samples were weighed accurately using an ESJ200-4A electronic analytical balance (Longteng Electronic Co. Ltd., Shenyang, China) with uncertainty of \pm 0.0001 g. A CY20A water thermostat (Boxun Industry \& Commerce Co. Ltd., Shanghai, China) with an uncertainty of $\pm 0.05 \mathrm{~K}$ and a DC-0506 lowconstant temperature bath (Hengping Instrument and Meter Factory, Shanghai, China) with an uncertainty of $\pm 0.05 \mathrm{~K}$ were applied to maintain the specific temperature of the system. Quantitative analysis was performed on a high-performance liquid chromatographic instrument equipped with a $250 \mathrm{~mm}$ Symmetry $\mathrm{C}_{18}$ column (4.6 $\mu \mathrm{m}$, Welchrom, Shanghai), a UV1201 detector and the EC2006 workstation (Elite Instrument Co., Ltd., Dalian, China). An N35 type neodymium magnet (Anpei Magnetic Industry Co. Ltd., Shanghai, China) was used in the experiment.

\subsection{Preparation of cholinium-based organic magnetic ionic liquids}

The cholinium-based organic magnetic ionic liquids were prepared according to the previously reported literature. ${ }^{31}$ In brief, two important intermediates, including alkyl-(2hydroxyethyl)-dimethylammonium bromides $\left(\left[\begin{array}{llll}\mathrm{N}_{1} & 1 & n & 2 \mathrm{OH}\end{array}\right] \mathrm{Br}, n\right.$ $=\mathrm{H}, 2,3,4,5)$ and sodium 4-sulfonatooxy-2,2,6,6-tetramethyl piperidine-1-yloxyl ([TEMPO-OSO 3$] \mathrm{Na})$ were synthesized and purified. Then, five cholinium-based MILs [ $\mathrm{N}_{1} 1 \quad n \quad$ 2OH] [TEMPO$\left.\mathrm{OSO}_{3}\right](n=\mathrm{H}, 2,3,4,5)$ were prepared by the metathesis reaction between $\left[\begin{array}{llll}\mathrm{N}_{1} & 1 & n & 2 \mathrm{OH}\end{array}\right] \mathrm{Br}$ and [TEMPO-OSO$\left.]_{3}\right] \mathrm{Na}$. Finally, reddish or dark-reddish viscous liquids were obtained.

\subsection{Phase diagrams and tie-lines}

Firstly, phase diagrams of five magnetic ionic liquids (MILs) were constructed using binodal curves, which were determined using the cloud point method by titration. ${ }^{32}$ The specific operation process was described as follows: a certain amount of the MIL was precisely weighed and placed into a colorimetric tube, then a known mass of the double-distilled water was added. A mixer was used to disperse the blend solution by stirring at high speed. The colorimetric tube was immersed in a jacketed glass vessel, and the temperature of the system was determined at $T=$ (298.15, 313.15 and 333.15) K. An inorganic salt solution of known mass fraction was then added drop-wise into the above homogeneous MIL solutions using an injection syringe until a turbid or cloudy system was obtained and a biphasic region appeared; the first binodal data point was obtained by recording the composition of this mixture. Subsequently, redistilled water 
was added drop-wise into the colorimetric tube to regain the clear one-phase system, and the above procedure was repeated multiple times and the related data were used to develop a complete binodal curve. The binodal curve was correlated according to the empirical nonlinear expression proposed by Merchuk: ${ }^{33}$

$$
w_{1}=a \times \exp \left(b w_{2}^{0.5}-c w_{2}{ }^{3}\right)
$$

where $w_{1}$ and $w_{2}$ are the mass fractions of the MILs and salts, respectively; $a, b$, and $c$ are constants obtained by the leastsquares regression of the experimental binodal data.

The tie lines were determined by a gravimetric method and the phase diagram data were obtained from eqn (1). ${ }^{33}$ The specific process was as follows: a mixture at the biphasic region was prepared by mixing an appropriate mass of MIL $\left(m_{1}\right)$, salt $\left(m_{2}\right)$, and water $\left(m_{3}\right)$ in a vessel, which was placed in a thermostated bath for $1 \mathrm{~h}$ with continuous stirring. The mixture was then centrifuged at $8000 \mathrm{rpm}$ for $10 \mathrm{~min}$ to achieve a complete phase separation the investigated systems were again placed in the thermostated bath. Afterwards, related samples obtained from the top and bottom phases were carefully weighed and their masses were marked as $m_{\mathrm{t}}$ and $m_{\mathrm{b}}$, respectively. On the basis of eqn (1) and the lever rule, the compositions of the top phase and bottom phase together with the total system at equilibrium were calculated using the eqn (2)-(5) via the MATLAB software (MathWorks, Natick, USA). ${ }^{34-36}$ The tie-line length (TLL) and the slope of the tie-line $(S)$ were also calculated using eqn (6) and (7) as shown below: ${ }^{35}$

$$
\begin{gathered}
\mathrm{w}_{1}^{\mathrm{t}}=a \times \exp \left[b\left(w_{2}^{\mathrm{t}}\right)^{0.5}-c\left(w_{2}^{\mathrm{t}}\right)^{3}\right] \\
w_{1}^{\mathrm{b}}=a \times \exp \left[b\left(w_{2}^{\mathrm{b}}\right)^{0.5}-c\left(w_{2}^{\mathrm{b}}\right)^{3}\right] \\
\left(w_{1}^{\mathrm{t}}-w_{1}\right) /\left(w_{1}-w_{1}^{\mathrm{b}}\right)=m_{\mathrm{b}} / m_{\mathrm{t}} \\
\left(w_{2}^{\mathrm{t}}-w_{2}\right) /\left(w_{2}-w_{2}^{\mathrm{b}}\right)=m_{\mathrm{b}} / m_{\mathrm{t}} \\
\mathrm{TLL}=\left[\left(w_{1}^{\mathrm{t}}-w_{1}^{\mathrm{b}}\right)^{2}+\left(w_{2}^{\mathrm{t}}-w_{2}^{\mathrm{b}}\right)^{2}\right]^{0.5} \\
S=\left(w_{1}^{\mathrm{t}}-w_{1}^{\mathrm{b}}\right) /\left(w_{2}^{\mathrm{t}}-w_{2}^{\mathrm{b}}\right)
\end{gathered}
$$

where $w_{1}^{\mathrm{t}}, w_{1}^{\mathrm{b}}, w_{2}^{\mathrm{t}}$, and $w_{2}^{\mathrm{b}}$ represent the equilibrium mass fraction of MILs (1) and salt (2) in the top phase (t) and bottom phases (b), respectively.

\subsection{Extraction with MIL-ATPs}

The extraction experiments for berberine hydrochloride were designed based on the magnetic ionic liquid-based aqueous twophase system (MIL-ATPs) and the obtained phase equilibrium data. In this study, a specific amount of MILs was placed into a $10 \mathrm{~mL}$ tube and mixed with a known concentration of berberine hydrochloride aqueous solution. Afterwards, a known amount of inorganic salt was added to the solution to form MIL-ATPs. The system was then placed in a water bath at constant temperature for a period of time, and the MIL phase (top phase) was separated by a magnet after thorough extraction. Finally, the concentrations of berberine hydrochloride at both the top phase and bottom phase were determined by HPLC. The upper phase (nearly $0.1 \mathrm{~mL}$ ) was diluted with redistilled water to $10 \mathrm{~mL}$ before it was injected into the HPLC for eliminating the matrix effect and getting the berberine concentration in the linear range of the work curve. The extraction efficiency $(E)$ and the partition coefficient $(K)$ were calculated according to the following equations:

$$
\begin{gathered}
E(\%)=\left(C_{\mathrm{t}} \times V_{\mathrm{t}}\right) / m \times 100 \% \\
K=C_{\mathrm{t}} / C_{\mathrm{b}}
\end{gathered}
$$

where $C_{\mathrm{t}}\left(\mathrm{mg} \mathrm{mL}^{-1}\right)$ and $C_{\mathrm{b}}\left(\mathrm{mg} \mathrm{mL}^{-1}\right)$ are the concentrations of berberine hydrochloride at the top phase and bottom phase, respectively. $V_{\mathrm{t}}(\mathrm{mL})$ is the volume of the top phase and $m(\mathrm{mg})$ is the total mass of berberine hydrochloride.

\subsection{Quantitative analysis of berberine hydrochloride}

HPLC was used to determine the content of berberine hydrochloride in the sample solution. Related analytical conditions were as follows: the mobile phase consisted of $0.1 \%(\mathrm{~V} / \mathrm{V})$ phosphoric acid aqueous solution-methanol $(70: 30)$; the flow

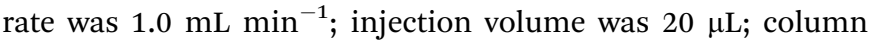
temperature was maintained at $25^{\circ} \mathrm{C}$; the detection wavelength was set at $345 \mathrm{~nm}$ according to a previous report. ${ }^{37}$ The calibration curve was performed by applying standard berberine hydrochloride solution at different concentrations $(0-40 \mu \mathrm{g}$ $\mathrm{mL}^{-1}$ ). As a result, the content of berberine hydrochloride was defined as its amount $(\mathrm{mg})$ determined by HPLC from a unit mass of dry herbal material $(\mathrm{g})$ after extraction.

\section{Results and discussion}

\subsection{Phase diagram and tie-lines}

3.1.1 The effect of magnetic ionic liquids on binodal curves. The binodal curve data for five MILs $\left(\begin{array}{llll}\mathrm{N}_{1} & 1 & \mathrm{H} & 2 \mathrm{OH}\end{array}\right]$

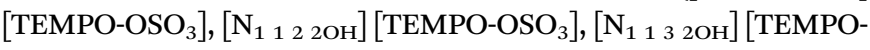

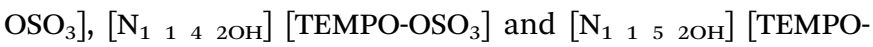
$\left.\left.\mathrm{OSO}_{3}\right]\right)+\mathrm{K}_{3} \mathrm{PO}_{4}+$ water MIL-ATPs are listed in the ESI (Table $\mathrm{S} 1 \dagger)$. The binodal experimental data were correlated according to eqn (1). The values of parameters $a, b$ and $c$ together with the corresponding standard deviations (SD) are presented in Table $\mathrm{S} 2, \dagger$ and the phase diagrams are shown in Fig. 1(a). The results indicate that the phase separation ability of the investigated MILs increase with the elongation of the carbon chain. Based on the structural similarity between ILs and surfactants, it was also found that MILs, just like some surfactant molecules, would self-assemble into aggregates in aqueous solution above the critical micellar concentration, ${ }^{38}$ which can realize partitioning of the target analyte into the magnetic-based IL. In general, the aggregates are globular micelles, which will speedily gather along one direction under appropriate conditions (e.g. external magnetic field). For the imidazolium-based ionic liquids, it was found in a previous study that the longer the alkyl chain on the cation, the higher their ability for phase formation. ${ }^{36}$ This basic trend is consistent with our findings in this study. In general, the hydrophobicity of the IL will become stronger when the carbon chain is longer. The formation of MIL-ATPs is a process 

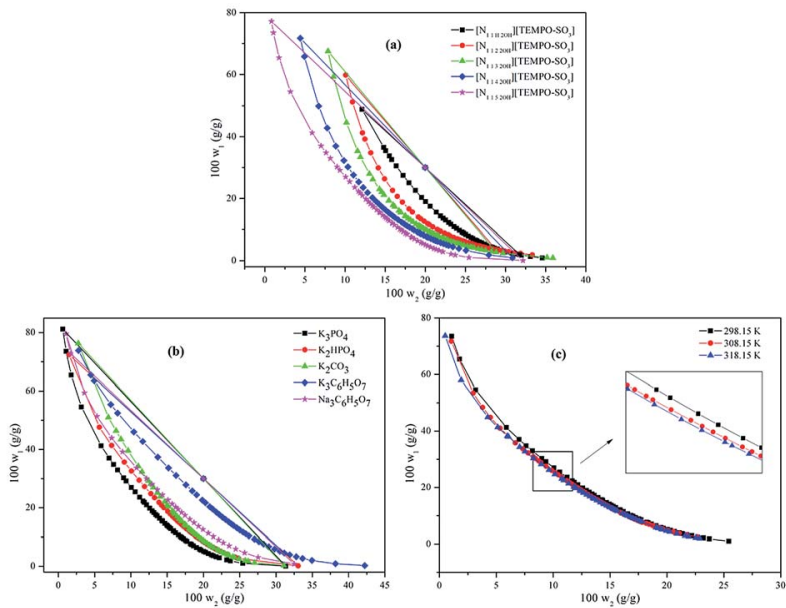

Fig. 1 Effects of magnetic ionic liquids of [ $\mathrm{N}_{1} 1 \mathrm{H}_{2} \mathrm{OH}$ ] [TEMPO-OSO $\mathrm{OS}_{3}$ ]

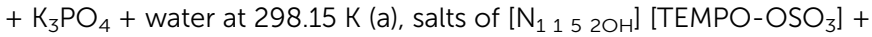
salts + water at $298.15 \mathrm{~K}$ (b) and temperature (c) of [ $\mathrm{N}_{1}{ }_{52} \mathrm{OH}_{\mathrm{H}}$ [TEMPO$\left.\mathrm{OSO}_{3}\right]+\mathrm{K}_{3} \mathrm{PO}_{4}+$ water on binodal curves and tie-lines for five MILs (1) + salts (2) + water (3) MIL-ATPs.

of the competition between MIL and inorganic salts for water molecules. The affinity of the inorganic salt towards water increases with the increase in the hydrophobicity of MILs. Therefore, the elongation of the cation carbon chain for MIL makes water transfer preferable from the top phase to the bottom phase, which results in the increase in the MIL concentration and the decrease in the salt dosage for the formation of ATPs. That is to say, the phase-formation ability of MILs grows stronger with the elongation of the cation carbon chain for MILs.

The tie-line compositions, including tie-line length (TLL) and the slope of the tie-line $(S)$ were obtained from eqn (2)-(7), and their values are listed in Table S3. $\dagger$ These experimental data are correlated by the Othmer-Tobias (eqn (10)) and Bancroft (eqn (11)) equations, which are given as follows: ${ }^{39}$

$$
\begin{aligned}
\left(1-w_{1}^{\mathrm{t}}\right) / w_{1}^{\mathrm{t}} & =k_{1}\left[\left(1-w_{2}^{\mathrm{b}}\right) / w_{2}^{\mathrm{b}}\right]^{n} \\
w_{3}^{\mathrm{b}} / w_{2}^{\mathrm{b}} & =k_{2}\left(w_{3}^{\mathrm{t}} / w_{1}^{\mathrm{t}}\right)^{r}
\end{aligned}
$$

where $w_{1}^{\mathrm{t}}, w_{2}^{\mathrm{b}}, w_{3}^{\mathrm{b}}$ and $w_{3}^{\mathrm{t}}$ are the mass fraction of MILs (1), salt (2) and water (3) in the top phase (t) and bottom phase (b), respectively. $k_{1}, n, k_{2}$ and $r$ are the fitting parameters. The values of these fitting parameters were obtained according to the slopes and intercepts of the plots $\log \left[\left(1-w_{1}^{\mathrm{t}}\right) / w_{1}^{\mathrm{t}}\right]$ against $\log [(1$ $\left.\left.-w_{2}^{\mathrm{b}}\right) / w_{2}^{\mathrm{b}}\right]$ together with $\log \left(w_{3}^{\mathrm{b}} / w_{2}^{\mathrm{b}}\right)$ against $\log \left(w_{3}^{\mathrm{t}} / w_{1}^{\mathrm{t}}\right)$. A good linear relationship indicates the acceptable consistency of the experimental results. The values of these fitting parameters of eqn (10) and (11) with the corresponding correlation coefficient values $\left(R^{2}\right)$ are listed in Table S4. $\uparrow$ The tie-lines for five MILs (1) + $\mathrm{K}_{3} \mathrm{PO}_{4}(2)+$ water (3) systems with the same phase composition are compared and illustrated in Fig. 1(a). As shown in Table S3, $\dagger$ it is obvious that the tie-line length increases with the elongation of Othmer-Tobias cation alkyl chain length.

3.1.2 The effect of inorganic salts on binodal curves. In order to explore the effect of different salts on the phase behavior of MILs and obtain the ideal ATPs, the binodal curve

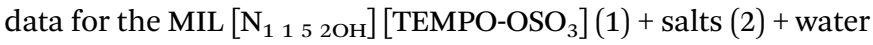
(3) MIL-ATPs were investigated and listed in the ESI $\dagger$ (Table S5 $\dagger$ ). Similarly, the binodal experimental data were correlated according to eqn (1). The values of parameters $a, b$ and $c$ along with the corresponding standard deviations (SD) are given in Table S2, $\dagger$ and the phase diagrams are shown in Fig. 1(b).

The phase diagrams can provide relevant information about the concentrations of MILs and salts required to form aqueous two-phase systems. The larger the two-phase region is, the stronger the ability of the inorganic salt to induce the MIL-ATPs formation. ${ }^{35}$ As shown in Fig. 1(b), for five investigated MILs, the abilities of five inorganic salts $\left(\mathrm{K}_{3} \mathrm{PO}_{4}, \mathrm{~K}_{2} \mathrm{HPO}_{4}, \mathrm{~K}_{2} \mathrm{CO}_{3}, \mathrm{~K}_{3} \mathrm{C}_{6} \mathrm{H}_{5} \mathrm{O}_{7}\right.$ and $\mathrm{Na}_{3} \mathrm{C}_{6} \mathrm{H}_{5} \mathrm{O}_{7}$ ) for phase-separation are in the following order: $\mathrm{K}_{3} \mathrm{PO}_{4}>\mathrm{K}_{2} \mathrm{HPO}_{4}>\mathrm{K}_{2} \mathrm{CO}_{3}>\mathrm{Na}_{3} \mathrm{C}_{6} \mathrm{H}_{5} \mathrm{O}_{7}>\mathrm{K}_{3} \mathrm{C}_{6} \mathrm{H}_{5} \mathrm{O}_{7}$. For the investigated inorganic salts, the salting-out ability of the anions follows the order: $\mathrm{PO}_{4}{ }^{3-}>\mathrm{HPO}_{4}{ }^{2-}>\mathrm{CO}_{3}{ }^{2-}>\mathrm{C}_{6} \mathrm{H}_{5} \mathrm{O}_{7}{ }^{3-}$ when they share the same cation. The previous study has shown that the abilities of the salts for ATPs formation for imidazolium-based ionic liquids are in complete agreement with our results. ${ }^{39,40}$ These anions exhibit a strong interaction with water molecules, which is beneficial to the MIL-ATPs formation. Many studies have shown that the salting-out ability can be related to the Gibbs free energy of hydration $\left(\Delta_{\text {hyd }} G\right)$ of the salt ions. ${ }^{41-43}$ Furthermore, there is also evidence that increasing entropy is the driving force for the two-phase formation. ${ }^{\mathbf{4}}$ For these salting-out inducing ions (also known as kosmotropes), the increase in the entropy of hydration $\left(\Delta_{\text {hyd }} S\right)$ can result in the dehydration of the solute and the increase in the surface tension. ${ }^{45-47}$ The absolute values of $\Delta_{\text {hyd }} G$ and $\Delta_{\text {hyd }} S$ for anions are in the order of $\mathrm{PO}_{4}{ }^{3-}\left(\Delta_{\text {hyd }} G=\right.$ $\left.-2765 \mathrm{~kJ} \mathrm{~mol}^{-1}, \Delta_{\text {hyd }} S=-421 \mathrm{~J} \mathrm{~K}^{-1} \mathrm{~mol}^{-1}\right)>\mathrm{HPO}_{4}{ }^{2-}\left(\Delta_{\text {hyd }} G=\right.$ $\left.-1789 \mathrm{~kJ} \mathrm{~mol}^{-1}, \Delta_{\mathrm{hyd}} S=-272 \mathrm{~J} \mathrm{~K}^{-1} \mathrm{~mol}^{-1}\right)>\mathrm{CO}_{3}{ }^{2-}\left(\Delta_{\text {hyd }} G=\right.$ $\left.-1315 \mathrm{~kJ} \mathrm{~mol}^{-1}, \Delta_{\text {hyd }} S=-245 \mathrm{~J} \mathrm{~K}^{-1} \mathrm{~mol}^{-1}\right) .{ }^{48}$ The abovereported results are in accordance with the order of the saltingout ability of anions. Among the investigated anions, the strongest salting-out inducing anion is $\mathrm{PO}_{4}{ }^{3-}$, which was also observed by others. ${ }^{49}$ This is attributable to the higher valence of $\mathrm{PO}_{4}{ }^{3-}$ compared to other anions. ${ }^{35}$ Compared with the two-phase region of $\mathrm{Na}_{3} \mathrm{C}_{6} \mathrm{H}_{5} \mathrm{O}_{7}$ and $\mathrm{K}_{3} \mathrm{C}_{6} \mathrm{H}_{5} \mathrm{O}_{7}$, it was found that the saltingout ability of cations follows the order: $\mathrm{Na}^{+}>\mathrm{K}^{+}$for the citratebased salts, which is accordant with the literature. ${ }^{50}$ Similarly, the absolute values of $\Delta_{\text {hyd }} G$ and $\Delta_{\text {hyd }} S$ for $\mathrm{Na}^{+}$and $\mathrm{K}^{+}$are in the order $\mathrm{Na}^{+}\left(\Delta_{\text {hyd }} G=-365 \mathrm{~kJ} \mathrm{~mol}^{-1}, \Delta_{\text {hyd }} S=-111 \mathrm{~J} \mathrm{~K}^{-1} \mathrm{~mol}^{-1}\right)>$ $\mathrm{K}^{+}\left(\Delta_{\text {hyd }} G=-295 \mathrm{~kJ} \mathrm{~mol}^{-1}, \Delta_{\text {hyd }} S=-74 \mathrm{~J} \mathrm{~K}^{-1} \mathrm{~mol}^{-1}\right)$. The effect of cations on the salting-out ability for cholinium-based MILs follows the Hofmeister series. ${ }^{48}$ Additionally, the same order of salting-out ability of five inorganic salts was also observed for the four other MILs in this study. The tie-line compositions, including tie-line length (TLL) and the slope of the tie-line $(S)$ are listed in Table S3. $\dagger$ The values of these fitting parameters of eqn (10) and (11) with the corresponding correlation coefficient values $\left(R^{2}\right)$ are listed in Table $\mathrm{S} 4 . \dagger$

3.1.3 The effect of temperature on binodal curves. The effect of temperature on the phase-separation ability of MILATPs was investigated and is illustrated in Fig. 1(c). The binodal curves data for the MIL $\left[\begin{array}{llll}\mathrm{N}_{1} & 1 & 5 & 2 \mathrm{OH}\end{array}\right]$ [TEMPO-OSO 3 (1) + $\mathrm{K}_{3} \mathrm{PO}_{4}(2)+$ water (3) MIL-ATPs at different temperatures are 
listed in Table S6. $\dagger$ The binodal experimental data were correlated according to eqn (1). The values of parameters $a, b$ and $c$ together with the corresponding standard deviations (SD) are given in Table $\mathrm{S} 2 . \dagger$

As shown in Fig. 1(c), the two-phase region for the MIL $\left[\mathrm{N}_{1} 15\right.$ ${ }_{20 H}$ [TEMPO-OSO 3$]+\mathrm{K}_{3} \mathrm{PO}_{4}+$ water system shows a slight increase with the increase in temperature, which indicates that high temperature is beneficial to the formation of MIL-ATPs. The formation of an aqueous two-phase system is essentially attributed to the diversity of the hydrate-forming ability for salt and MIL. In the two components, the salts have the stronger hydration ability and are usually considered as the kosmotrope (water structure-maker), and the other (MIL) is described as the water structure-breaker. ${ }^{51}$ The possible reason is that the hydration ability of the salt $\mathrm{K}_{3} \mathrm{PO}_{4}$ increases with an increase in temperature. As a result, water is driven preferably from the MIL-rich phase to the salt-rich phase, which improves the phase-separation ability. Another possible reason is that the MIL-solvent interaction decreases with an increase in temperature, which leads to the decrease in the solubility of MIL in water and facilitates the formation of MIL-ATPs. This phenomenon is consistent with that observed in other aqueous two-phase systems. ${ }^{\mathbf{5 2 , 5 3}}$ Interestingly, the phase-forming ability of some ionic liquids, such as imidazolium-based ionic liquids, ${ }^{54}$ pyridinium-based ionic liquids ${ }^{55}$ and amino acid ionic liquids $^{56}$ decreases with increasing temperature, which is opposite to our results. The tie-line compositions, including tieline length (TLL) and the slope of the tie-line $(S)$ are listed in Table S3. $\uparrow$ The values of these fitting parameters of eqn (10) and (11) with the corresponding correlation coefficient values $\left(R^{2}\right)$ are listed in Table S4. $\dagger$

\subsection{Extraction of berberine hydrochloride in MIL-ATPs}

3.2.1 Effect of different MILs. The effect of five MILs on the partition coefficient $(K)$ and extraction efficiency $(E)$ of berberine hydrochloride was investigated and the results are shown in Fig. 2(a). A certain amount of MILs (0.5 g, 10\%) was dissolved in a certain volume of distilled water. Then, $1.5 \mathrm{~g}$ of $\mathrm{K}_{3} \mathrm{PO}_{4}$ was added to make the mass ratio up to $30 \%$. Finally, $2 \mathrm{~mL}$ solution of berberine hydrochloride with the concentration of $0.5 \mathrm{mg}$ $\mathrm{mL}^{-1}$ was added to the mixture. As shown in Fig. 2(a), both the partition coefficient and extraction efficiency increase with the elongation of the alkyl chain on the cation. The result is related to the phase separation ability of MILs, while the intermolecular force also makes MIL have a strong dissolving ability for the target alkaloid. As previously mentioned in Section 3.1.1, the phase separation ability of five MILs can increase when the carbon chain becomes longer. The trend is consistent with the partition coefficient and the extraction efficiency of berberine hydrochloride. Another possible reason is that berberine hydrochloride can dissolve in ILs by the electrostatic interaction of the anion [TEMPO-OSO $]_{3}^{-}$with the electron-deficient pyridine ring in its structure. The electrostatic interaction can be strengthened by the elongation of alkyl chain on the cation, which makes the MIL with the longer alkyl chain have the better extraction efficiency for berberine hydrochloride. Additionally,
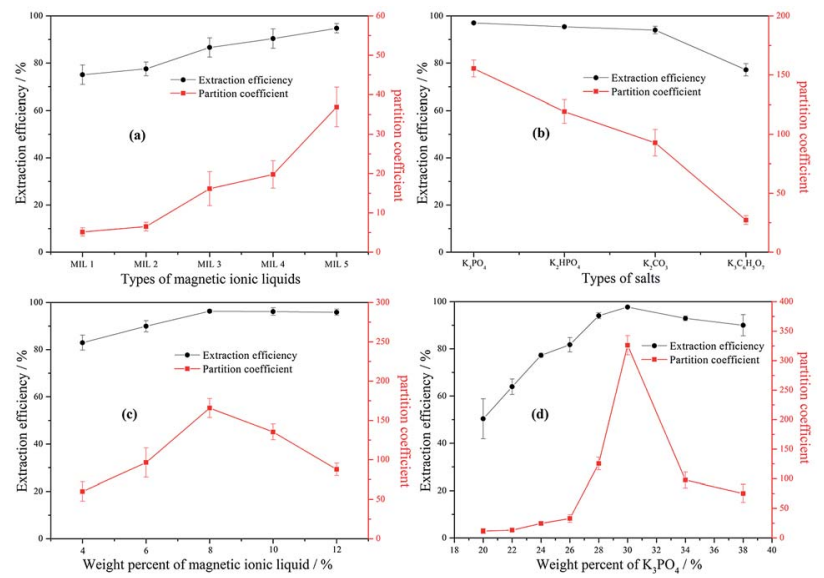

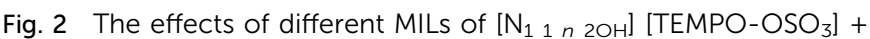
$\mathrm{K}_{3} \mathrm{PO}_{4}+$ water (a), different salts of $\left[\mathrm{N}_{1} 1_{22} \mathrm{OH}\right]\left[\mathrm{TEMPO}-\mathrm{OSO}_{3}\right]+$ salts + water (b), weight percent of MIL of [ $\left.\mathrm{N}_{11} 5_{2} \mathrm{OH}\right]$ [TEMPO-OSO 3 ] $\mathrm{K}_{3} \mathrm{PO}_{4}$ + water (c) and weight percent of $\mathrm{K}_{3} \mathrm{PO}_{4}$ of [ $\mathrm{N}_{1} 15_{2} \mathrm{CHH}_{\text {] }}$ [TEMPO-OSO $+\mathrm{K}_{3} \mathrm{PO}_{4}+$ water (d) on the partition coefficient and extraction efficiency of berberine hydrochloride: MIL $1=\left[\begin{array}{llll}\mathrm{N}_{1} & 1 & \mathrm{H} & 2 \mathrm{OH}\end{array}\right]$ [TEMPO-

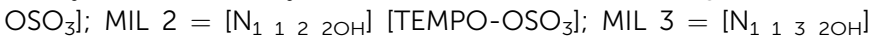

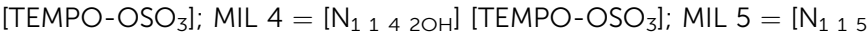
$2 \mathrm{OH}$ ] [TEMPO-OSO 3 .

the hydroxyl and benzene ring are conducive to the formation of hydrogen bonds and dispersion interactions, respectively. ${ }^{57}$

3.2.2 The effect of the type of salt. In order to evaluate the effect of the salt types on the partition coefficient and extraction efficiency of berberine hydrochloride in $\left[\begin{array}{llll}\mathrm{N}_{1} & 1 & 5 & 2 \mathrm{OH}\end{array}\right]$ [TEMPO$\left.\mathrm{OSO}_{3}\right]+$ salts + water system MIL-ATPs, four kosmotropic salts, including $\mathrm{K}_{3} \mathrm{PO}_{4}, \mathrm{~K}_{2} \mathrm{HPO}_{4}, \mathrm{~K}_{2} \mathrm{CO}_{3}, \mathrm{~K}_{3} \mathrm{C}_{6} \mathrm{H}_{5} \mathrm{O}_{7}$, were chosen. The weight percents of MIL and salt were kept constant at $10 \mathrm{wt} \%$ and $30 \mathrm{wt} \%$, respectively, and the experimental results are illustrated in Fig. 2(b). In the case of using $\mathrm{K}_{3} \mathrm{PO}_{4}, \mathrm{~K}_{2} \mathrm{HPO}_{4}$, $\mathrm{K}_{2} \mathrm{CO}_{3}$ and $\mathrm{K}_{3} \mathrm{C}_{6} \mathrm{H}_{5} \mathrm{O}_{7}$, ATPS was formed under the condition of $1.5 \mathrm{~g}$-salt/0.5 g-MIL/3 mL-water. The effect of the salts on the extraction of berberine hydrochloride followed the order of $\mathrm{K}_{3} \mathrm{PO}_{4}>\mathrm{K}_{2} \mathrm{HPO}_{4}>\mathrm{K}_{2} \mathrm{CO}_{3}>\mathrm{K}_{3} \mathrm{C}_{6} \mathrm{H}_{5} \mathrm{O}_{7}$, which was in agreement with the phase-separation ability of these four inorganic salts. In summary, the stronger the phase-forming ability is, the better the extraction effect is. The stronger phase-forming ability leads the MIL to preferably transfer from the bottom phase to the top phase, which can result in the increase in the amount of berberine hydrochloride at the top phase. On the other hand, the effect of salt types on the partition coefficient is more significant than that on extraction efficiency, and it can also be found in the above and following studies for other influencing factors.

3.2.3 The effect of the weight percent of MIL. In order to determine the effect of the MIL amount on the partition coefficient and extraction efficiency of berberine hydrochloride at room temperature, the different weight percents of the

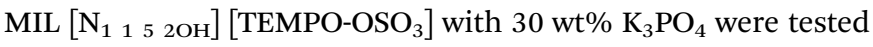
(see Fig. 2(c)). The results can prove that both the partition coefficient and the extraction efficiency of berberine hydrochloride can become higher by increasing the amount of the MIL until extraction saturation. At the earlier stage, the 
extraction efficiency of berberine hydrochloride increases along with the increasing amount of MIL, which could be attributed to the greater number of MIL available for berberine hydrochloride at a larger amount of the MIL. When the weight percent of MIL is more than $8 \%$, no significant change is observed. However, the partition coefficient of berberine hydrochloride showed an initial increase, followed by a slight decrease. This is mainly because the volume of the top phase and the bottom phase increases and decreases, respectively, with the increasing amount of the MIL. The partition coefficient and extraction efficiency simultaneously reach the maximum value at the weight percent of $8 \mathrm{wt} \%$ MIL.

3.2.4 The effect of the weight percent of $\mathrm{K}_{3} \mathrm{PO}_{4}$. According to the phase equilibrium behavior in Section 3.1, the effects of $\mathrm{K}_{3} \mathrm{PO}_{4}$ at different weight percents $(20,22,24,26,28,30,34$ and $38 \mathrm{wt} \%$ ) on the partition coefficient and extraction efficiency of berberine hydrochloride were studied. The weight percent of

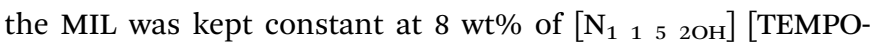
$\left.\mathrm{OSO}_{3}\right]$ in all experiments. The results obtained from the influence of salt on the berberine hydrochloride partitioning are shown in Fig. 2(d). It was observed that the weight percent of salt has a significant effect on the partition coefficient and extraction efficiency of berberine hydrochloride; both of them increase and then decrease with the increasing weight percent of $\mathrm{K}_{3} \mathrm{PO}_{4}$. The berberine hydrochloride prefers to exist in the top phase (MIL-rich phase) for its strong interaction with MIL. Moreover, the increase in the weight percent of $\mathrm{K}_{3} \mathrm{PO}_{4}$ facilitates the formation of two phases, which helps the MIL transfer preferably from the salt-rich phase to the MIL-rich phase. Therefore, the partition coefficient and extraction efficiency will become higher when the weight percent of $\mathrm{K}_{3} \mathrm{PO}_{4}$ increases. However, they reach the maximum value at the weight percent of $30 \mathrm{wt} \% \mathrm{~K}_{3} \mathrm{PO}_{4}$. When the weight percent of $\mathrm{K}_{3} \mathrm{PO}_{4}$ is beyond $30 \mathrm{wt} \%$, the partition coefficient and extraction efficiency decrease with the further increase in $\mathrm{K}_{3} \mathrm{PO}_{4}$. This is ascribed to the ion intensity of the system increasing continuously so that the tendency of berberine hydrochloride towards the bottom phase increased, which led to the decrease in the partition coefficient and extraction efficiency. Therefore, $30 \mathrm{wt} \%$ of $\mathrm{K}_{3} \mathrm{PO}_{4}$ was chosen as the weight percent of salt for the extraction of berberine hydrochloride.

3.2.5 The effect of the concentration of berberine hydrochloride. Fig. 3(a) shows the partition coefficient and extraction efficiency for different concentrations of berberine hydrochlo-

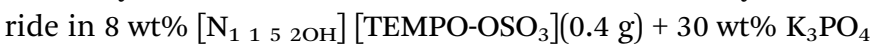
$(1.5 \mathrm{~g})+$ water system. The range of berberine hydrochloride concentration in the MIL-ATPs varied between $0.05 \mathrm{mg} \mathrm{mL}^{-1}$ and $0.3 \mathrm{mg} \mathrm{mL}{ }^{-1}$. For the studied range of sample concentration, no significant change in extraction efficiency was observed. This proves that the MIL $\left[\begin{array}{llll}\mathrm{N}_{1} & 1 & 5 & 2 \mathrm{OH}\end{array}\right]$ [TEMPO-OSO 3 has a high partition coefficient and extraction efficiency for berberine hydrochloride within a wider concentration range. In addition, both the partition coefficient and extraction efficiency reached their maximum values when the concentration of berberine hydrochloride was $0.25 \mathrm{mg} \mathrm{mL}^{-1}$.

3.2.6 The effect of extraction time. To explore the appropriate extraction time for berberine hydrochloride in the MIL-

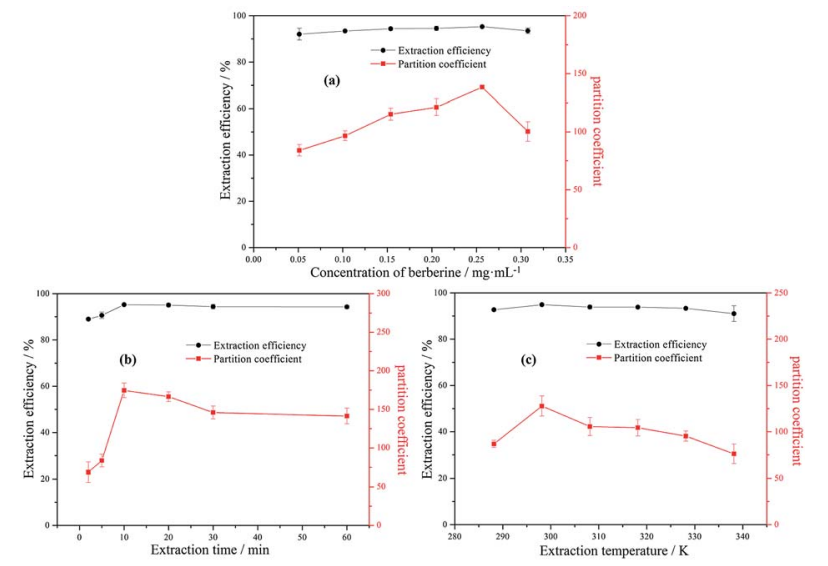

Fig. 3 The effects of the concentration of berberine hydrochloride (a), time (b) and temperature (c) on the partition coefficient and extraction efficiency of berberine hydrochloride in [ $\mathrm{N}_{1} 15_{2} 2 \mathrm{OH}$ [ [TEMPO-OSO $\left.\mathrm{S}_{3}\right]+$ $\mathrm{K}_{3} \mathrm{PO}_{4}+$ water MIL-ATPs.

ATPs of $\left[\begin{array}{llll}\mathrm{N}_{1} & 1 & 5 & 2 \mathrm{OH}\end{array}\right]$ [TEMPO-OSO 3$]+\mathrm{K}_{3} \mathrm{PO}_{4}+$ water, various durations (0-60 $\mathrm{min}$ ) were also investigated and the experimental results are shown in Fig. 3(b). It was found that both the partition coefficient and the extraction efficiency of berberine hydrochloride become higher when the extraction time increases from $0 \mathrm{~min}$ to $10 \mathrm{~min}$. However, a further increase in the ultrasonic extraction time can result in a slight decrease in the partition coefficient. This phenomenon can be explained by a competition of opposing processes. A longer extraction time provides more thorough contact of water with berberine hydrochloride, which may cause the target compound to move preferably to the bottom phase. Compared with the extraction of vitamin $\mathrm{B}_{6}$ using the ionic liquid aqueous two-phase system for $8 \mathrm{~h},{ }^{\mathbf{5}}$ the extraction time of berberine hydrochloride is much shorter in this study. It proves that MIL shows a stronger affinity with the target alkaloid. Moreover, vitamin $\mathrm{B}_{6}$ is more soluble in water than berberine hydrochloride, which makes this kind of vitamin transfer preferably to the bottom phase and leads to a longer extraction time. In conclusion, $10 \mathrm{~min}$ was sufficient for the extraction for berberine hydrochloride to obtain a high partition coefficient and extraction efficiency.

3.2.7 The effect of extraction temperature. The effect of temperature (from 288.15 to $338.15 \mathrm{~K}$ ) on the partition coefficient and extraction efficiency of berberine hydrochloride in $8 \mathrm{wt} \%\left[\mathrm{~N}_{11} 5_{2} \mathrm{OH}\right][$ TEMPO-OSO 3$](0.4 \mathrm{~g})+30 \mathrm{wt} \% \mathrm{~K}_{3} \mathrm{PO}_{4}(1.5 \mathrm{~g})+$ water MIL-ATPs was studied. The results are presented in Fig. 3(c). There was no significant change in the partition coefficient and extraction efficiency in the temperature range of $288.15 \mathrm{~K}$ to $338.15 \mathrm{~K}$; therefore, the temperature has less effect on the extraction of berberine hydrochloride and the method has good thermal universality and stability. As such, the extraction experiments can be conducted at room temperature in order to simplify the operation.

\subsection{Method validation}

The performance of this method based on MIL-ATPs combined with HPLC was investigated and evaluated with respect to 
linearity, inter- and intra-day precision, recovery, limit of detection (LOD) and limit of quantification (LOQ). The calibration curve was prepared based on the linear regression analysis of the peak area versus concentration. As a result, the obtained linear regression equation was $y=(5.65 \pm 0.03) \times$ $10^{-1} x+(0.59 \pm 0.69) \times 10^{-1}$ for the developed ATPs-HPLC analysis, where $x$ was the concentration $\left(\mu \mathrm{g} \mathrm{mL}^{-1}\right)$ of berberine hydrochloride and $y$ was the UV absorbance value of the related peak area, respectively. Nine calibration levels from 0 to $40 \mu \mathrm{g} \mathrm{mL}^{-1}$ were used to obtain the calibration curve. The correlation coefficient $\left(R^{2}=0.9999\right)$ indicated that the working curve had a good linear relationship in the above concentration range, which is wider than that of the fluorimetric method with silica nanoparticles as the probe $\left.\left(2.0-50.0 \times 10^{-3} \mu \mathrm{g} \mathrm{mL}\right)^{-1}\right)^{59}$ and capillary electrophoresis $\left(0.1-13.4 \mu \mathrm{g} \mathrm{mL}{ }^{-1}\right)^{60}$ for the same quantitative analysis of berberine.

For the precision, the intra-day and inter-day variation was determined using $20 \mu \mathrm{g} \mathrm{mL} \mathrm{m}^{-1}$ of berberine hydrochloride standard solution with six replications under the optimum conditions and expressed as the relative standard deviation (RSD). The RSD values for intra-day and inter-day precision were $1.40 \%(n=6)$ and $2.83 \%(n=3)$, respectively. Moreover, the recovery for three different concentrations was calculated according to the following equation: recovery $(\%)=$ (concentration after spiking - concentration of original)/spiked concentration $\times 100$. The results were also satisfactorily in the range of $97.4-101.2 \%$. Finally, the LOD and LOQ values for berberine hydrochloride were $0.023 \mathrm{mg} \mathrm{L}^{-1}$ and $0.077 \mathrm{mg} \mathrm{L}^{-1}$, based on the signal-to-noise ratio of 3 and 10, respectively. The validation results indicated that this method had a good sensitivity and reliability for the quantitation of berberine hydrochloride. Compared with the reported electrochemical analysis (LOD: $0.0329 \mathrm{mg} \mathrm{L}^{-1}$ ) ${ }^{61}$ and nonaqueous capillary electrophoresis (LOD: $0.31 \mathrm{mg} \mathrm{L^{-1 }}$ ) $^{62}$ for berberine, the proposed method has a lower LOD. The above results prove that the MIL-ATPs-HPLC has unique features among the reported techniques with different characteristics and can make its own contribution to the quantitative analysis of target alkaloids.

\subsection{Analysis of herbal samples}

To investigate the actual extraction performance and content of the target alkaloid in potential herbal samples, the proposed method was applied to the quantitative analysis of berberine hydrochloride in the extract of Rhizoma coptidis. Firstly, the dried roots of the raw material were ground into a homogeneous size and sieved through a 40-mesh filter. Then, $10.0 \mathrm{~g}$ of herbal powder was extracted with distilled water $(60 \mathrm{~mL})$ for $1.5 \mathrm{~h}$ under reflux. At the end of the extraction, the extract was filtered and concentrated to $10 \mathrm{~mL}$ under vacuum at $60^{\circ} \mathrm{C}$. Next, $1.0 \mathrm{~mL}$ of the extract was diluted to $10 \mathrm{~mL}$ and the analyte from the real herbal sample was obtained. Under the same optimal conditions, the final enrichment factor of berberine hydrochloride in the $\left[\mathrm{N}_{1} 152 \mathrm{OH}\right]\left[\right.$ TEMPO-OSO $\left.{ }_{3}\right]+\mathrm{K}_{3} \mathrm{PO}_{4}+$ water ATP system was 127.68. The experimental results are illustrated in Fig. 4 . The maximum UV absorption wavelength of the MILs is $245 \mathrm{~nm},{ }^{31}$ whereas the detection wavelength in HPLC analysis was set at $345 \mathrm{~nm}$. Meanwhile, the retention time of MIL and berberine was around 4.8 and $7.7 \mathrm{~min}$, respectively; there was no interfering absorption signal coming from the MILs. The enrichment selectivity is ascribed to the difference in intermolecular interaction between berberine-MIL and coexisting MILcompounds. For instance, for protoberberines, it was determined by the difference in substituent groups and their locations, polarity, solubility and partition behaviour between berberine and similar alkaloids. The two methoxy groups in the D ring of berberine can form a long conjugated chain with the benzene ring, and it is easier to become an electron donor ${ }^{63}$ and provide stronger electrostatic interactions with MIL. Moreover, it is obvious that the reddish top phase containing the target alkaloid can be easily attracted by a magnet and was assembled for sampling prior to chromatographic analysis. The volume of the upper phase for the analysis of herbal samples was $0.11 \mathrm{~mL}$. As a result, the berberine hydrochloride content in the raw material of Rhizoma coptidis was determined as $123.95 \mathrm{mg} \mathrm{g}^{-1}$. As validation, the content was also determined as $124.02 \mathrm{mg} \mathrm{g}^{-1}$ (mean value of three replicates) according to the method cited in the Chinese pharmacopoeia (ChP, 2015 edition).

\subsection{Recovery of the top phase containing MIL after quantitative analysis}

In conventional analytical research, the recovery of related reagents after quantitation work is always ignored, because their consumption is much less than that in preparative separation. Considering the expense of ILs synthesis, this section was specially designed for MIL recovery to save the cost of the above analytical work and realize its recycling for 'green' principles. After the extraction and analysis, the top phase of ATPs contained MIL, $\mathrm{K}_{3} \mathrm{PO}_{4}$ and berberine hydrochloride, together with other co-existing constituents extracted from the herbal material. Though ILs have obvious advantages over volatile

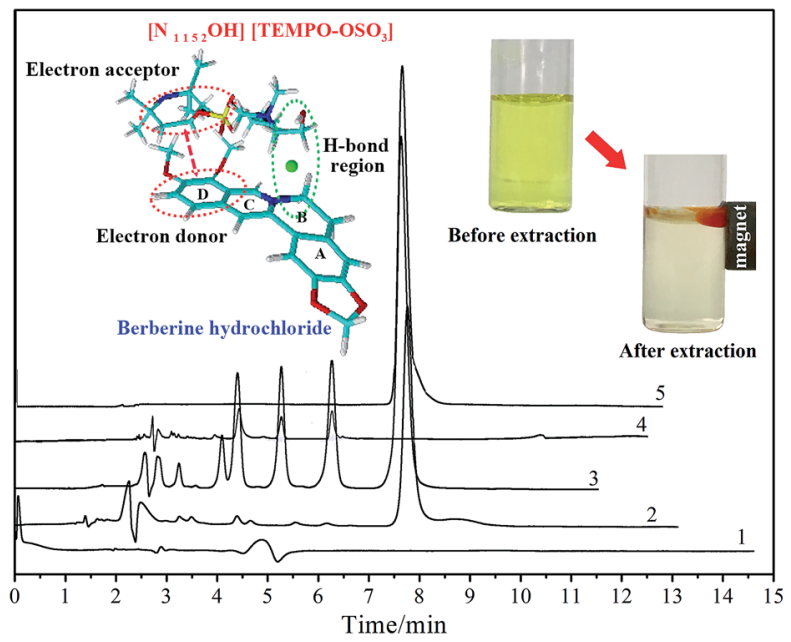

Fig. $4 \mathrm{HPLC}$ chromatograms of $\left[\begin{array}{llll}\mathrm{N}_{1} & 1 & 5 & 2 \mathrm{OH}\end{array}\right]$ [TEMPO-OSO 3 (1), the upper phase (2), crude extract (3), lower phase (4) and berberine hydrochloride standard solution (5), together with molecular simulation results. Mobile phase: $0.1 \%(V / V)$ phosphoric acid aqueous solution-methanol (70:30); flow rate: $1.0 \mathrm{~mL} \mathrm{~min}^{-1}$; column temperature: $25^{\circ} \mathrm{C}$; detection wavelength: $345 \mathrm{~nm}$. 
organic solvents, they should be efficiently recovered for the consideration of their environmental and economic aspects. In order to reuse the top phase containing MIL and realize cycle application, an effective separation method for the top phase and those extracted compounds should be developed. The backextraction with organic solvent has been used in previous research. ${ }^{64}$ Here, both MIL and berberine hydrochloride are the compounds with similar polarity and dissolution behavior so that it is difficult to separate them by simple partition between water and organic solvents. Therefore, the solid-liquid adsorption method was adopted and D101 resin showed the strong selective adsorption capacity for berberine hydrochloride and other extracted constituents. The specific operation was shown as follows: $0.1 \mathrm{~mL}$ of MIL-rich phase was diluted with distilled water to $10 \mathrm{~mL}$ and placed in a conical flask. Then, $0.1 \mathrm{~g}$ of D101 resin was added, and the conical flask was placed in a water-bath shaker $(200 \mathrm{rpm})$ at room temperature for $20 \mathrm{~min}$. After complete adsorption, the solution was centrifuged at $8000 \mathrm{rpm}$ for $3 \mathrm{~min}$. The concentrations of MIL and berberine hydrochloride in the supernatant were determined and the results indicated that $\left[\begin{array}{llll}\mathrm{N}_{1} & 1 & 5 & 2 \mathrm{OH}\end{array}\right]$ [TEMPO-OSO 3$]$ and $\mathrm{K}_{3} \mathrm{PO}_{4}$ could not be adsorbed by this kind of resin, and still existed in the solution. After the simple solid-liquid separation, 99.8\% MIL was recovered according to HPLC analysis, which could be reused in the next extraction and quantitation process. According to the purity investigation of recovered IL, it can be reused at least four times and then its purity will be below $90 \%$.

\section{Conclusions}

In this study, the MIL-ATPs were developed for the selective enrichment and quantitative analysis of berberine hydrochloride from Rhizoma coptidis, which was composed of five cholinium-based organic magnetic ionic liquids and inorganic salts including $\mathrm{K}_{3} \mathrm{PO}_{4}, \quad \mathrm{~K}_{2} \mathrm{HPO}_{4}, \quad \mathrm{~K}_{2} \mathrm{CO}_{3}, \quad \mathrm{~K}_{3} \mathrm{C}_{6} \mathrm{H}_{5} \mathrm{O}_{7}$ and $\mathrm{Na}_{3} \mathrm{C}_{6} \mathrm{H}_{5} \mathrm{O}_{7}$. It was found that [ $\left[\begin{array}{llll}\mathrm{N}_{1} & 1 & 5 & 2 \mathrm{OH}\end{array}\right]$ [TEMPO-OSO 3 ] and $\mathrm{K}_{3} \mathrm{PO}_{4}$ had the best performance for phase formation. Interestingly, the phase-formation ability of MIL-ATPs increased with the increasing temperature; i.e., a high temperature is conducive to the formation of MIL-ATPs, which is opposite to the phase behavior of other ILs. The possible reason is that the hydration ability of the $\mathrm{K}_{3} \mathrm{PO}_{4}$ salt increases with an increase in temperature. As a result, water is driven preferably from the MIL-rich phase to the salt-rich phase, which improves the phase-separation ability. Moreover, MIL-solvent interaction decreases with an increase in temperature.

In the following analytical application, the MIL-ATPs based

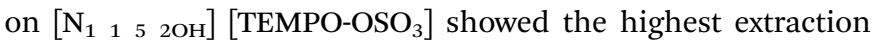
efficiency for the target alkaloid among the investigated systems. Under optimal extraction conditions, the partition coefficient of berberine hydrochloride could reach 127.68. Finally, the feasibility of the method was validated and satisfactory results were obtained, which indicate a good linear range of $0-40 \mu \mathrm{g} \mathrm{mL} \mathrm{mL}^{-1}$ with the precision $\mathrm{RSD} \%$ (1.40\% for intra-day and $2.83 \%$ for inter-day precisions). The limit of detection $\left(0.023 \mathrm{mg} \mathrm{L}^{-1}\right)$ and limit of quantification $\left(0.077 \mathrm{mg} \mathrm{L}^{-1}\right)$ were obtained. Furthermore, good recovery in the range of $97.4-101.2 \%$ for berberine hydrochloride was also achieved by this method. Additionally, this method was used to determine the content of berberine hydrochloride in the raw material of Rhizoma coptidis and the result was $123.95 \mathrm{mg} \mathrm{g}^{-1}$. Finally, MIL could be recovered through the adsorption method after HPLC analysis. This study is expected to provide a meaningful reference for the extraction and analysis of natural products by MIL-ATPs from complex samples.

\section{Conflicts of interest}

We declare that we have no conflict of interest.

\section{Acknowledgements}

This paper was supported by the National Natural Science Foundation of China (No. 81673316) and "Stars of Chemical Engineering" outstanding young talent training program of Sichuan University (2017).

\section{Notes and references}

1 R. Y. Gan, Int. J. Mod. Biol. Med., 2012, 2012, 48-81.

2 A. L. Souto, J. F. Tavares, M. S. da Silva, M. F. F. M. Diniz, P. F. de Athayde-Filho and J. M. Barbosa Filho, Molecules, 2011, 16(10), 8515-8534.

3 Y. T. Ho, C. C. Lu, J. S. Yang, J. H. Chiang, T. C. Li, S. W. Ip, T. C. Hsia, C. L. Liao, J. G. Lin and W. G. Wood, Anticancer Res., 2009, 29(10), 4063-4070.

4 R. Ke, K. Vishnoi, N. Viswakarma, S. Santha, S. Das, A. Rana and B. Rana, Sci. Rep., 2018, 8(1), 5521.

5 Y. C. Cai, Q. Xia, R. Z. Luo, P. Y. Huang, Y. L. Sun, Y. X. Shi and W. Q. Jiang, J. Nat. Med., 2014, 68(1), 53-62.

6 C. R. Naveen, S. Gaikwad and R. Agrawal-Rajput, Phytomedicine, 2016, 23(7), 736-744.

7 A. B. G. Aghaie and M. R. Hadjmohammadi, Talanta, 2016, 156-157, 18-28.

8 B. Liu, W. Li, Y. Chang, W. Dong and L. Ni, J. Pharm. Biomed. Anal., 2016, 41(3), 1056-1060.

9 H. L. Shi, S. L. Peng, J. Sun, Y. M. Liu, Y. T. Zhu, L. S. Qing and X. Liao, J. Sep. Sci., 2014, 37(6), 704-710.

10 L. Jiang, B. Chen, B. Chen, X. Li, H. Liao, W. Y. Zhang and L. Wu, J. Sep. Sci., 2017, 40(14), 2933-2940.

11 N. Li, Y. Z. Wang, K. J. Xu, Y. H. Huang, Q. Wen and X. Q. Ding, Talanta, 2016, 152, 23-32.

12 Y. Zheng, Y. Tong, S. Wang, H. Zhang and Y. Yang, Sep. Purif. Technol., 2015, 154, 123-127.

13 X. Yang, S. Zhang, W. Yu, Z. Liu, L. Lei, N. Li, H. Zhang and Y. Yu, Talanta, 2014, 124(13), 1-6.

14 A. M. Ferreira, J. A. P. Coutinho, A. M. Fernandes and M. G. Freire, Sep. Purif. Technol., 2014, 128(325), 58-66.

15 K. E. Gutowski, G. A. Broker, H. D. Willauer, J. G. Huddleston, R. P. Swatloski, J. D. Holbrey and R. D. Rogers, J. Am. Chem. Soc., 2003, 125(22), 6632-6633.

16 Y. Pei, J. Wang, K. Wu, X. Xuan and X. Lu, Sep. Purif. Technol., 2009, 64(3), 288-295. 
17 Q. Liu, Y. Jiang, W. Li, X. Hu, H. Xia, H. Liu and P. Yang, Sep. Sci. Technol., 2006, 41(12), 2849-2858.

18 M. Dominguez-Perez, L. I. N. Tome, M. G. Freire, I. M. Marrucho, O. Cabeza and J. A. P. Coutinho, Sep. Purif. Technol., 2010, 72(1), 85-91.

19 Q. Cao, L. Quan, C. He, N. Li, K. Li and F. Liu, Talanta, 2008, 77(1), 160-165.

20 Z. Du, Y. L. Yu and J. H. Wang, Chem.-Eur. J., 2007, 13(7), 2130-2137.

21 X. X. Liu, Z. Y. Li, Y. C. Pei, H. Y. Wang and J. J. Wang, J. Chem. Thermodyn., 2013, 60, 1-8.

22 W. Zhang, D. Zhu, H. J. Fan, X. Q. Liu, Q. Wan, X. H. Wu, P. Liu and J. Z. Tang, Sep. Purif. Technol., 2015, 141, 113-123.

23 A. He, B. Dong, X. T. Feng and S. Yao, Sep. Purif. Technol., 2018, 196, 270-280.

24 S. Shahriari, L. C. Tome, J. M. M. Araujo, L. P. N. Rebelo, J. A. P. Coutinho, I. M. Marrucho and M. G. Freire, $R S C$ Adv., 2013, 3, 1835-1843.

25 Z. Li, X. Liu, Y. Pei, J. Wang and M. He, Green Chem., 2012, 14, 2941-2950.

26 T. Mourao, L. C. Tome, C. Florindo, L. P. N. Rebeló and I. M. Marrucho, ACS Sustainable Chem. Eng., 2014, 2, 24262434.

27 M. Petkovic, J. L. Ferguson, H. N. Gunaratne, R. Ferreira, M. C. Leitao, K. R. Seddon, L. P. N. Rebelo and C. S. Pereira, Green Chem., 2010, 12, 643-649.

28 J. F. B. Pereira, F. Vicente, V. C. Santos-Ebinuma, J. M. Araújo, A. Pessoa, M. G. Freire and J. A. P. Coutinho, Process Biochem., 2013, 48(4), 716-722.

29 T. Yao, S. Yao, D. Tang, L. Jing, D. C. Wang and H. Song, RSC Adv., 2016, 6(58), 52898-52904.

30 E. Santos, J. Albo and A. Irabien, RSC Adv., 2014, 4, 4000840018.

31 L. R. Nie, S. Yao, B. Dong, X. L. Li and H. Song, J. Mol. Liq., 2017, 240, 152-161.

32 P. A. Albertsson, Partition of Cell Particles and Macromolecules,3rd edn, Wiley, New York, 1986.

33 J. C. Merchuk, B. A. Andrews and J. A. Asenjo, J. Chromatogr. B: Biomed. Sci. Appl., 2012, 1238(1-2), 285-293.

34 J. Chen, S. K. Spear, J. G. Huddleston, J. D. Holbrey, R. P. Swatloski and R. D. Rogers, Ind. Eng. Chem. Res., 2004, 43(17), 5358-5364.

35 C. X. Li, J. Han, Y. Wang, Y. S. Yan, J. M. Pan, X. H. Xu and Z. L. Zhang, J. Chem. Eng. Data, 2010, 55(3), 1087-1092.

36 J. Han, Y. Wang, C. Chen, W. B. Kang, Y. Liu, K. K. Xu and L. Ni, J. Mol. Liq., 2014, 193, 23-28.

37 W. J. Kong, Y. L. Zhao, L. M. Shan, X. H. Xiao and W. Y. Guo, Acta Chim. Sin., 2008, 66(22), 2533-2538.

38 P. Brown, A. Bushmelev, C. P. Butts, J. Cheng, J. Eastoe, I. Grillo, R. K. Heenan and A. M. Schmidt, Angew. Chem., Int. Ed. Engl., 2012, 124(10), 2464-2466.

39 W. Liang, Z. Hong, C. Ma, Y. Yan and Q. Wang, J. Chem. Eng. Data, 2012, 57(3), 681-687.
40 S. C. Silvério, O. Rodríguez, J. A. Teixeira and E. A. Macedo, J. Chem. Eng. Data, 2013, 58(12), 3528-3535.

41 Y. Wang, X. H. Xu, Y. S. Yan, J. Han and Z. L. Zhang, Thermochim. Acta, 2010, 501(1), 112-118.

42 S. H. Li, C. Y. He, H. W. Liu, K. Li and F. Liu, J. Chromatogr. B, 2005, 826(1-2), 58-62.

43 M. Holz, R. Grunder, A. Sacco and A. Meleleo, J. Chem. Soc., Faraday Trans., 1993, 89(8), 1215-1222.

44 M. T. Zafarani-Moattar and V. Hosseinpour-Hashemi, J. Chem. Eng. Data, 2012, 57(2), 532-540.

45 M. G. Freire, P. J. Carvalho, A. M. S. Silva, L. M. N. B. F. Santos and J. A. P. Coutinho, J. Phys. Chem. $B, 2009,113(1), 202-211$.

46 L. I. N. Tome, F. R. Varanda, M. G. Freire, I. M. Marrucho and J. A. P. Coutinho, J. Phys. Chem. B, 2009, 113(9), 2815-2825.

47 M. G. Freire, C. M. S. S. Neves, A. M. S. Silva, L. M. N. B. F. Santos, I. M. Marrucho, L. P. N. Rebelo, J. K. Shah, E. J. Maginn and J. A. P. Coutinho, J. Phys. Chem. B, 2010, 114(5), 2004-2014.

48 S. Shahriari, C. M. Neves, M. G. Freire and J. A. Coutinho, J. Phys. Chem. B, 2012, 116(24), 7252.

49 N. J. Bridges, K. E. Gutowski and R. D. Rogers, Green Chem., 2007, 9(2), 177-183.

50 X. Rico-Castro, M. González-Amado, A. Soto and O. Rodríguez, J. Chem. Thermodyn., 2017, 108, 136-142.

51 M. T. Zafarani-Moattar and S. Hamzehzadeh, J. Chem. Eng. Data, 2009, 54(3), 833-841.

52 X. Q. Xie, Y. S. Yan, J. Han, Y. Wang, G. W. Yin and W. S. Guan, J. Chem. Eng. Data, 2010, 55(8), 2857-2861.

53 M. T. Zafarani-Moattar, S. Emamian and S. Hamzehzadeh, J. Chem. Eng. Data, 2008, 53(2), 456-461.

54 J. Han, R. Pan, X. Q. Xie, Y. Wang, Y. S. Yan, G. W. Yin and W. X. Guan, J. Chem. Eng. Data, 2010, 55(9), 3749-3754.

55 Y. L. Li, M. S. Zhang, Q. Liu and H. Su, J. Chem. Thermodyn., 2013, 66, 80-87.

56 C. Z. Wu, J. J. Wang, H. Y. Wang, Y. C. Pei and Z. Y. Li, J. Chromatogr. A, 2011, 1218(48), 8587-8593.

57 N. Du, S. W. Cao and Y. Y. Yu, J. Chromatogr. B, 2011, 879(19), 1697-1703.

58 Y. L. Li, X. J. Lu, Q. Zhu, R. Huang, J. Hu, H. B. Yang and Y. L. Yao, Fluid Phase Equilib., 2016, 430, 101-111.

59 Q. Liu, Z. H. Xie, T. Liu and J. Fan, RSC Adv., 2018, 8, 60756082.

60 S. Uzasci and F. B. Erim, J. Chromatogr. A, 2014, 1338, 184187.

61 A. Geto, M. Pita, A. L. De Lacey, M. Tessema and S. Admassie, Sens. Actuators, B, 2013, 183, 96-101.

62 W. H. Gao, S. Y. Lin, L. Jia, X. K. Guo, X. G. Chen and Z. D. Hu, J. Sep. Sci., 2005, 28, 92-97.

63 P. P. Miao, Y. Y. Zhao, Q. Miao, C. E. Guo, H. Y. Chen, N. Chen, Y. J. Zhang and S. C. Ma, Chin. J. New Drugs, 2016, 6, 705-711.

64 Z. Yang, Z. Tan, F. Li and X. Li, Ind. Crops Prod., 2016, 89, 7886. 